\title{
Life satisfaction in adolescents: the role of individual and social health assets
}

Luis Calmeiro Inês Camacho Margarida Gaspar de Matos

This article has been published in a revised form in Spanish Journal of Psychology,

DOI: https://doi.org/10.1017/sjp.2018.24

This version is free to view and download for private research and study only. Not for re-distribution, re-sale or use in derivative works. (C) Universidad Complutense de Madrid and Colegio Oficial de Psicólogos de Madrid 2018 


\title{
Life Satisfaction in Adolescents: The Role of Individual and Social Health
}

\section{Assets}

\author{
Luis Calmeiro ${ }^{1}$, Inês Camacho², and Margarida Gaspar de Matos ${ }^{2}$
}

University of Abertay Dundee (UK)

Universidade de Lisboa (Portugal)

(TNW No. 12) Correspondence concerning this article should be addressed to Luis Calmeiro. University of Abertay Dundee. Division of Sport and Exercise Sciences. DD1 1HG Dundee, Scotland, UK. E-mail: 1.calmeiro@abertay.ac.uk

\section{How to cite this article:}

Calmeiro, L., Camacho, I., \& de Matos, M. G. (2018). Life Satisfaction in adolescents: The role of individual and social health assets. The Spanish Journal of Psychology, 21. eXX.

Doi:XXXXXXXXXX. 


\begin{abstract}
The aim of this study is to explore the relationship between adolescents' life satisfaction and individual and social health assets. A nationally representative sample of 3,494 Portuguese adolescents (mean age $=14.94 \pm 1.30$ years; $53.6 \%$ girls) completed the Health Behavior in School-aged Children survey measuring a variety of health behaviors and beliefs. A sequential regression analysis was conducted with gender, individual assets (academic achievement, social competence, self-regulation and life objectives) and social assets (family support, peer support, parental monitoring and school connectedness) entered in separate steps. A second regression analysis was conducted with social assets entered before individual assets. The final model explained $18.3 \%$ of life satisfaction. School connectedness $(\beta=.198, p<.001)$ and family support $(\beta=.154, p<.001)$ were the strongest predictors of adolescents' life satisfaction followed by social competence $(\beta=.152, p<.001)$, academic achievement $(\beta=.116, p<.001)$ and self-regulation $(\beta=.064, p<.001)$. Social assets explained a larger variance of life satisfaction than individual assets when entered first in the regression $\left(r^{2}=.134\right.$ and $r^{2}=.119$, respectively, $p<.001)$. When entered last step in the regression analysis, social assets added more to life satisfaction's variance than when individual assets were added in the last step $\left(r^{2}\right.$ $=.060$ and $r^{2}=.045$, respectively, $\left.p<.001\right)$. These results reinforce the role social interaction and social capital models in the promotion of well-being.
\end{abstract}

Keywords: adolescents' health, quality of life, social support, well-being. 
Health promotion has progressively focused on the development of the capacity for individuals and communities to be actively engaged in the enhancement of their own health. Such promotion ensues when individuals and communities actively operate a number of health assets. According to the assets model (Morgan \& Ziglio, 2007), a health asset is "any factor (or resource) which maximizes the opportunities for individuals, local communities and populations to attain and maintain health and wellbeing" (p. 18). The identification of these factors or resources facilitates the delivery of interventions that optimize these individual and community health protective and promoting factors, empowering the communities to be collaborative partners in the production of health instead of passive consumers of healthcare services (Lerner \& Benson, 2003). Therefore, health promotion focusses on the development of assets suggesting the adoption of a comprehensive approach that emphasizes not only the reduction of risk factors but also the increase of protective factors (Scales, 1999).

Scales (1999) identified and categorized 40 factors into internal and external assets. Internal assets represent "values, skills and competencies young people develop to guide themselves, to become self-regulating" (p. 113). External assets refer to the "relationships and opportunities adults provide young people" (p. 113). Therefore, health assets rest within the individual or exist within the social environment or community where individuals live (Morgan $\&$ Ziglio, 2007). A number of individual assets have been identified in the literature; these include social competence, resilience, commitment to learning, positive values, self-esteem and sense of purpose. Supportive family and friendship networks, community cohesion and affinity groups are known community assets. Therefore, feeling socially connected and a sense of belonging to relevant contexts where social interactions evolve (e.g., school connectedness) are important factors to consider.

Researchers have shown that health assets are associated with quality of life (Murphey, Lamonda, Carney, \& Duncan, 2004; Proctor, Linley, \& Maltby, 2010). The more assets adolescents have the fewer risk behaviors they will engage in and the more positive outcomes they will experience. For example, Murphey et al. (2004) found that the number of assets people possess was inversely related to engagement in risk behaviors (e.g., smoking, alcohol abuse, physical fighting), and positively related to health-promoting behaviors (e.g., exercise, safety belt use). Differentiating the effects of individual and social assets in quality of life will facilitate the prioritization of targeted interventions.

Concerning individual assets, perceptions of competence have been a central topic in human motivation (Bandura, 1997; Ryan \& Deci, 2000). Competence encompasses multiple dimensions within youth functioning such as academic competence and social competence 
(Catalano, Berglund, Ryan, Lonczak, \& Hawkins, 2004). Academic competence is an indication of cognitive competence relevant to intellectual achievement and it has been suggested to be the strongest protective factor against risk behaviors (Murphey et al. 2004). Social competence is vital for the achievement of specific social and interpersonal goals and involves the use of interpersonal skills such as interpreting social cues, conflict resolution or making social decisions (Catalano et al., 2004).

Self-regulation is an individual asset that allows individuals to exercise control over their behavior and their emotional states to pursue personally relevant goals or desired outcomes (Vohs \& Baumeister, 2004). Self-regulation represents the adolescents' ability to monitor their activities, evaluate their performance, motivate themselves and maintain their resilience while experiencing school and social disappointments (Zimmerman, 2002). Therefore, this concept appears to be fundamental for adolescents to maintain balance and satisfaction in life through the ability to exert control over their lives in difficult situations.

In line with a broad definition of health, health is the capacity of individuals and communities to ultimately develop and pursue their life goals and dreams (Frasquilho, de Matos, Gaspar, \& Almeida, 2014). Holding high and positive expectations for the future has been linked with more positive perceptions of one's position in life in relation to one's values, standards and concerns (Edwards, Huebner, Connell, \& Patrick, 2002). Being optimistic about one's life and personal future, and having purpose in life helps develop a sense of positive identity (Scales, 1999). Maintaining a positive expectation about the future, having goals and making plans to pursue one's dreams have been shown to be associated with higher life satisfaction. This is particularly important in Portugal as adolescents from low social economic backgrounds living in socioeconomic deprivation are unlikely to obtain high levels of education (Frasquilho et al., 2014). In addition, adolescents from impoverished backgrounds have lower levels of life satisfaction (Klanšček, Žiberna, Korošec, Zurc, \& Albreht, 2014), which should make underserved populations a priority for interventions.

Concerning social assets, social connectedness and school connectedness are important resources. While social connectedness represents the quality of adolescents' social network, school connectedness represents the extent to which students feel accepted, respected, included and supported in school (Gerard \& Booth, 2015; Murphey et al., 2004).

Social connectedness has been referred to as the main precursor of youth adjustment (Guerra \& Bradshaw, 2008). Indeed, adequate social support was found to moderate the impact of stress on health among adolescents (Dumont \& Provost, 1999). Conversely, dissatisfaction with social support has been linked to depression, anxiety and poor sleep (Bond et al, 2007). In 
addition to feeling cared for, a sense of connectedness also involves caring about the social environment, which strengthens a sense of belonging (Guerra \& Bradshaw, 2008). This sense of belonging develops in relation to family, friends, neighborhood or institutions in which adolescents grow (e.g., sport clubs, schools). Social environments that provide adolescents with positive resources from significant others (e.g., family, schools) tend to facilitate more adaptive behavioral patterns and more positive development (Youngblade, et al., 2007).

The family context is central to the development of well adjusted, resilient adolescents. For example, perceptions of the quality of family engagement and closeness between family members, communication and parental role modelling were associated with perceptions of social competence, self-esteem and health-promoting behavior among adolescents (Youngblade et al., 2007). Moreover, parental monitoring was positively associated with health-promoting behaviors such as dieting and physical activity, and negatively associated with sedentary behaviors in youngsters at risk of becoming obese (Lawman \& Wilson, 2012).

The health assets discussed above are resources that adolescents may develop to improve their quality of life. Therefore, the purpose of this study is to explore the associations between adolescents' satisfaction with their life and individual and social assets. Specifically, we intend to determine the relative importance of these types of assets in a nationally representative sample of Portuguese school-aged adolescents. We focus in adolescents as this a stage of development when attitudes towards lifestyle and personal control tend to be developed and exploratory behavior with potential risk taking ensues (Lerner \& Steinberg, 2009).

Based on the extant literature, it is expected that adolescents who perceive themselves to be academically and socially competent, with the ability to self-regulate, and who have meaningful life goals to pursue are more likely to be more satisfied with their lives. Moreover, it is hypothesized that adolescents who perceive family and peer support, have meaningful family relationships and experience a degree of parental monitoring as well as a sense of connectedness with school will be more satisfied with their quality of life. Although it is likely that individual and social assets uniquely contribute to adolescents' quality of life, we do not advance a hypothesis concerning which set of assets will be the stronger predictor of life satisfaction in adolescents.

\section{Method}

\section{Participants and procedure}


The sample for this study is composed by 3,494 participants (mean age $=14.94 \pm 1.30$ years), of which 1,872 were girls (53.6\%) and 1,622 were boys (46.4\%). Participants were students in the $8^{\text {th }}(45.6 \%)$ and $10^{\text {th }}$ grades $(54.4 \%)$.

This study was based on the Health Behavior in School-aged Children (HBSC) Portuguese 2010 survey (Matos et al., 2011). After approval from the ethics commission of S. Joao Hospital, and the National Committee for Data Protection, 139 schools were randomly selected taken from a list of the Ministry of Education and stratified by administrative region. Fifty-two schools were selected from the north region (corresponding to $40 \%$ of respondents), 24 from Centre region (corresponding to $15.2 \%$ of respondents) 41 from Lisbon and Vale do Tejo region (30.1\%), 7 from Alentejo (6.3\%), 6 from Algarve (4.9\%), and 9 from Madeira region $(3.5 \%)$. Head teachers were contacted to request participation. Then, informed consent and parental consent for completion of the HBSC survey were obtained. Surveys were sent to schools by mail with procedural instructions for teachers' administration during regular class time. After completion of the surveys, these were collected and returned by mail. Data collection and survey procedures were conducted following the HBSC international protocol, which are fully described elsewhere (Currie et al., 2008; de Matos et al., 2011; Roberts et al., 2009). The response rate at school level was $92 \%$ and at both class and student levels it was $87 \%$.

\section{Measures}

\section{Outcome measure}

Life Satisfaction was assessed by Cantril's self-anchoring ladder measurement technique (Cantril, 1965). This technique consists of the presentation of one ladder with 10 steps ranging from the worst possible life (step 0 ) to the best possible life (step 10). Adolescents were asked to indicate the step of the ladder that best represented their satisfaction with their lives at the moment. The reliability, construct validity and convergent validity of this measure for this age group were supported by theoretically consistent patterns of correlations with validated measures of emotional well-being, perceived health, and subjective health (Levin \& Currie, 2014).

\section{Individual assets}

Predictor or independent variables represent individual and social health assets. To be included in the HBSC survey study, all questions must be valid and reliable to be used with children in the various participating countries (Iannotti et al., 2009; Roberts et al., 2009). We now define the individual assets measures chosen from the HBSC survey. Academic achievement was measured with a single-item asking participants the question "Compared to 
your colleagues, how would you rate your academic ability?" Answers were given in a 4-point Likert scale $(1=$ very good to $4=$ below average $)$. Social competence was assessed by the average of six 7-point Likert scale items $(1=$ always false, $7=$ always true $)$. Sample items include "I feel I am a competent person", or "I feel very close and intimate" and followed the stem sentence "In my relationship in general" $(\alpha=.72)$. Self-regulation was measured by the average of five items (e.g., "When I am sad, I usually do something that makes me feel good"; "I am able to resist doing something that I know I shouldn't do"). Answers were recorded in 5point Likert scales ranging from $1=$ never to true to $5=$ always true $(\alpha=.78)$. Life goals was assessed by the average of two 5-point Likert scale items ( 1 = never; $5=$ always $)$ : "I have goals and plans for the future" and "I have objectives/meaning for my life" $(\alpha=.85)$.

\section{Social assets}

Concerning the social assets, we now describe the variables selected from the HBSC survey. Family support was assessed by the average of 4 items, including "My family tries to help me" and "I can talk to my family about my problems". Answers are given on a 7-point Likert scale, ranging from $1=$ strongly disagree to $7=$ strongly agree $(\alpha=.92)$. Peer support is the average of 4 items, including "My friends try to help me" and "I have friends with whom I can share my joy and sadness". Answers were given on a 7-point Likert scale, ranging from 1 $=$ strongly disagree to $7=$ strongly agree $(\alpha=.92)$. Parental monitoring assessed the level monitoring parents appear to exert over participants. Following the stem "How much do your parents know about...", participants answered five items, including "who your friends are", and "Where you are after school". Answers were recorded in a 4-point scale ( 1 = they know a lot, 2 = they know a bit, $3=$ they don't know anything, $4=$ don't have or see my parents). The internal consistency for this scale was appropriate $(\alpha=.84)$. School connectedness is understood here as the degree of satisfaction with the quality of relationships within the school. This variable is the average of 3 items: In my school... "Students like being together", "students are kind and helpful" and "students accept me". Answers were given in a 5-point Likert scale that ranged from 1 = strongly agree to $5=$ strongly disagree. Scores were reversed-coded and the internal consistency of this scale was acceptable $(\alpha=.70)$.

\section{Data analysis}

Descriptive statistics were calculated for all variables, and then converted into $z$-scores. The $z$-scores were used in a sequential (hierarchical) multiple regression procedure in which quality of life was regressed on gender and school grade as control variables (Step 1), followed by variables that represented individual assets (Step 2) and social assets (Step 3). A second sequential multiple regression was conducted with social assets entered in Step 2 and individual 
assets entered in Step 3. In addition to $\Delta R^{2}$ as a statistics that can test for statistical significance at each step, the unsquared metrics, square root $\Delta R^{2}\left(\sqrt{ } \Delta R^{2}\right)$ is also reported as a measure of importance to compare magnitude of the effects between each step of the sequential regression (Keith, 2014). Beta coefficients lower than .05 were considered too small to be meaningful; beta coefficients lower than .10 were considered small but meaningful; higher than 0.10 were moderate and higher than .25 were considered large. All statistical analyses were conducted on IBM SPSS 22.0 version and the level of significance was set at .05.

Data screening was conducted prior to the main regression analyses. Durbin-Watson test values close to 2 and variation inflation factor values close to 1 suggest that collinearity was not an issue in the analyses. In line with expectations, twenty-five cases (less than $1 \%$ of the sample) with standardized residuals higher than an absolute value of 3 were identified. Cook's distance was lower than 1 in all cases indicating that there were no particularly influential observations in the database. Analyses of scatterplots of standardized residuals and predicted values indicate appropriate homoscedasticity while P-P plots indicate normality of residuals. Multivariate outliers were identified using Mahalanobis distance, and 72 cases with a value equal or higher than $26.27(p<.001)$ were deleted.

\section{$<\mathrm{H} 1>$ Results}

Descriptive statistics for all variables and correlation coefficients are presented in Table 1. All correlations were statistically significant, but more importantly, these ranged from weak $(r=.07)$ to moderate $(r=.44)$ and in the expected direction.

\section{<Insert Table 1 Here>}

Table 2 summarizes the results from the sequential multiple regression for the entire sample in which life satisfaction was regressed on demographic variables (Model 1), individual assets (Model 2) and social assets (Model 3). Table 3 shows the results of the hierarchical regression analysis with Steps 2 and 3, described in Table 2, reversed.

\section{<Insert Tables 2 and 3 Here>}

Overall, the model explains $18.3 \%$ of the variance of adolescents' life satisfaction. Gender becomes a non-significant variable in the regression analysis when individual or social assets are introduced in Step 3. When individual assets were entered as a block, after gender, there is a significant increase in the variance of life satisfaction, $\Delta R^{2}=.119, F$ change $(4,2814)$ $=95.63, p<.001$. Social assets were added in the third step and the results suggest a similar statistically significant effect in the variance of quality of life, $\Delta R^{2}=.06, F$ change $(4,2810)=$ 81.56, $p<.001$. (Table 2). 
When Steps 2 and 3 are reversed, social assets explain 13,4\% of life satisfaction's variance, $\Delta R^{2}=.134, F$ change $(4,2814)=109.56, p<.001$, while the introduction of individual assets in Step 3 only explains a further $4.5 \%$ of life satisfaction, $\Delta R^{2}=.045, F$ change $(4,2810)$ $=38.99, p<.001($ Table 3$)$.

At the final step (Model 3), family support $(\beta=.154, p<.001)$, and school connectedness $(\beta=.198, p<.001)$ were the social assets significantly associated with life satisfaction. In regard to individual assets, social competence $(\beta=.152, p<.001)$ and academic achievement $(\beta=.116, p<.001)$ and self-regulation $(\beta=.064, p<.001)$ were significant predictors of life satisfaction.

\section{Discussion}

The purpose of this paper was to explore the unique role of individual and social assets in adolescents' life satisfaction. Overall results indicate that individual assets and social assets significantly and independently predict adolescents' life satisfaction. In addition, social assets appear to explain more variance of life satisfaction than individual assets. However, the difference between both group of assets is small. These results may be explained by the fact that individual and social assets may share common features, and that individual assets are likely to develop within a social context. In fact, adolescents establish a number of social networks that provide a variety of resources for personal development. These networks constitute a form of social capital that provides the foundations for the development of bonding and bridging relationships, processes that support personal and social competence and growth (Calmeiro \& de Matos, 2016) and promote well-being (Bond et al., 2007; Gerard \& Booth, 2015).

Concerning specific health assets, family support and school connectedness (social assets) were the strongest predictors of life satisfaction among adolescents, followed by social competence, academic competence and self-regulation (individual assets). All variables had a moderate effect on life satisfaction, with the exception of self-regulation, which had a small but meaningful effect (Keith, 2006). These results are consistent, on one hand, with studies that underscore the importance of favorable family contexts for socio-emotional well-being, in which adolescents receive emotional support and sufficient resources (Gerard \& Booth, 2015). On the other hand, feeling valued by the community has been shown to be the strongest asset to protect against suicidal ideation in North-American high school students (Murphey et al., 2004). In the same way, low school connectedness has been associated with increased risk of 
anxiety and depressive symptoms as well as a number of risk behaviors indicating poor quality of life (Bond et al., 2007).

We hypothesized that individual assets would be associated with life satisfaction. This hypothesis was verified for academic achievement, social competence and self-regulation. Academic achievement represents cognitive ability and academic success and fulfils a basic psychological need to demonstrate competence (Ryan \& Deci, 2000). Moreover, self-efficacy is one of the most robust psychological variables associated with motivated behavior and psychological adjustment (Bandura, 1997). The present results confirm previous reports that suggest a negative association of academic achievement with risk behaviors and a positive association with health-promoting behaviors (Murphey et al., 2004) and life satisfaction (Proctor et al., 2010). Support for the relevance of social competence was also found by Proctor et al., 2010 and Suldo and Huebner (2006) who reported that high levels of social self-efficacy were related to high life satisfaction. Social competence may allow adolescents to develop meaningful relationships and capitalize on social resources. Consistent with the literature, selfregulation was a significant predictor of life satisfaction. Individuals who are able to selfregulate by monitoring their goals, exert self-control and delay gratification, or find appropriate social support are more likely to successfully adjust to academic, social and environmental challenges (Herndon, Bembenutty \& Gill, 2015; Zimmerman, 2002). This suggests that selfregulation may interact with other individual and social assets to promote positive health outcomes.

Against our expectations having life goals (cf. Gerard \& Booth, 2015; Proctor et al., 2010), and peer support (e.g., Bond et al., 2007; Proctor et al., 2010) were not associated with life satisfaction. In the present study, life goals were operationalized in general terms as having goals and expectations for the future. Perhaps respondents are yet to develop meaning and purpose in life, which should develop when their academic careers may affect more strongly their near future (e.g., studying for access to university). This hypothesis needs to be tested. Likewise, the results concerning peer support were also against expectations. It is possible that peer support did not emerge as a significant predictor of life satisfaction because school connectedness included items that addressed the level of satisfaction with schoolmates.

The present study has a number of limitations. First, this study is cross-sectional in nature; therefore, cause effect cannot be determined. Nevertheless, the results are consistent with other research, which indicates that these assets are worth considering for interventions (Morgan \& Haglund, 2009). Second, the data was collected through self-report and, therefore, can be subject to social desirability despite the fact that data collection procedures guaranteed 
anonymity. Third, variables were measured as a part of a larger survey, which resulted in the use general short measures of the variables of interest.

Nevertheless, a major strength of this study is the fact that the rigorous sampling procedures resulted in the selection of participants that constitute a nationally representative sample of the population of school-aged children. In addition, the identification of relevant health assets is particularly important in the context of the country's economic recession that impacts adolescents' health and quality of life. Therefore, educational authorities should consider the development and delivery of educational programs to counterbalance the impact of the economic recession that has put families and young people in privation. Programs to improve adolescents' connection to school have been scarce (Roth \& Brooks-Gunn, 2003), but to capitalize on the role of school connectedness, schools should focus on the development of a sense of community where students feel heard and cared for. Youth development programs generally aim at developing competence, confidence, connections, character and a caring attitude (Catalano et al., 2004). Programs should focus on the development of a variety of social and academic skills, and provide opportunities for students to experience mastery as a source of self-efficacy (Bandura, 1997). Roth and Brooks-Gunn (2003) documented that competencyenhancing goals, specifically the development of adolescents' social and cognitive skills, are among the most common goals for these programs. Activities that encourage adolescents to engage in life skills training, community service and develop leadership qualities to build a variety of competencies in a number of contexts (e.g., school, family, community) are necessary.

The present results also suggest that programs should focus on the development of the quality of family relationships as supportive relationships have been shown to be the basis of resilient adaptation to difficulties (Masten, 2001) and well-being (Ronen, Hamama, Rosenbaum, \& Mishely-Yarlap, 2016). For example, interventions that target parents to develop supportive communication or to encourage family involvement with school activities appear to be relevant for the creation of a supportive community in times of hardship. 


\section{References}

Bandura, A. (1997). Self-efficacy: The exercise of control. New York, NY: Freedman and Company.

Bond, L., Butler, H., Thomas, L., Carlin, J., Glover, S., Bowes, G., \& Patton, G. (2007). Social and school connectedness in early secondary school as predictors of late teenage substance use, mental health, and academic outcomes. Journal of Adolescent Health, 40, 357, e9. http:/doi.org/10.1016/j.jadohealth.2006.10.013

Calmeiro, L., \& de Matos, M. G. (2016). Health assets and active lifestyles during pre-adolescence and adolescence: Highlights from the HBSC/WHO health survey and implications for health promotion. In M. Raab, P. Wylleman, R. Seiler, A. Elbe, \& A. Hatzigeorgiadis (Eds.), Sport and exercise psychology research: From theory to practice (pp. 433-460). London: Academic Press. https://doi.org/10.1016/B978-0-12-803634-1.00020-0

Cantril, H. (1965). The pattern of human concerns. New Brunswick, NJ: Rutgers University Press.

Catalano, R. F., Berglund, M. L., Ryan, J. A. M., Lonczak, H. S., \& Hawkins, J. D. (2004). Positive youth development in the United States: Research findings on evaluations of positive youth development programs. The Annals of the American Academy of Political and Social Science, 591, 98-124. http://doi.org/10.1177/0002716203260102

Currie, C., Gabhainn, S. N., Godeau, E., Roberts, C., Smith, R., Currie, D., ... Barnekow, V. (2008). Inequalities in young people's health: HBSC international report from the 2005/2006 Survey (No. 5). Copenhagen, Denmark: WHO Regional Office for Europe.

De Matos, M. G., Simões, C., Tomé, G., Camacho, I., Ferreira, M., Ramiro, ... Equipa Aventura social (2011). A saúde dos adolescentes portugueses. Relatório do estudo HBSC 2010 [The health of Portuguese adolescents. Report of the 2010 HBSC study]. Faculdade de Motricidade Humana, Cruz-Quebrada. http://aventurasocial.com/arquivo/1334762276 Relatorio HBSC 2010 PDF Finalissimo.pdf

Dumont, M., \& Provost, M. A. (1999). Resilience in adolescents: Protective role of social support, coping strategies, self-esteem, and social activities on experience of stress and depression. Journal of Youth and Adolescence, 28, 343-363. http://doi.org/10.1023/A:1021637011732

Edwards, T. C., Huebner, C. E., Connell, F. A., \& Patrick, D. L. (2002). Adolescent Quality of Life, part I: Conceptual and measurement model. Journal of Adolescence, 25, 275-286. http://doi.org/10.1006/jado.2002.0470

Frasquilho, D., de Matos, M. G., Gaspar, T., \& Almeida, J. M. C. (2014). Do adolescents' future expectations differ by parental employment situation? Highlights from the Portuguese HBSC/WHO survey. International Journal of Development Research, 4, 1981-1986.

Gerard, J. M., \& Booth, M. Z. (2015). Family and school influences on adolescents' adjustment: The moderating role of youth hopefulness and aspirations for the future. Journal of Adolescence, 44, 1-16. http://doi.org/10.1016/j.adolescence.2015.06.003

Guerra, G., \& Bradshaw, C. P. (2008). Linking the prevention of problem behaviors and positive youth development: Core competencies for positive youth development and risk prevention. New Directions for Child and Adolescent Development, 122, 1-17. http://doi.org/10.1002/cd.225

Herndon J. S., Bembenutty, H., \& Gill, M. G. (2015). The role of delay of gratification, substance abuse, and violent behavior on academic achievement of disciplinary alternative middle school students. Personality and Individual Differences, 86, 44-49. http://doi.org/10.1016/j.paid.2015.05.028

Iannotti, R. J., Janssen, I., Haug, E., Kololo, H., Annaheim, B., Borraccino, A., \& Physical Activity Focus Group (2009). Interrelationships of adolescent physical activity, screen-based sedentary behavior, and social and psychological health. International Journal of Public Health, 54 (Supp. 2), 191-198. http://doi.org/10.1007/s00038-009-5410-Z

Klanšček, H. J., Žiberna, J., Korošec, A., Zurc, J., \& Albreht, T. (2014). Mental health inequalities in Slovenian 15-year-old adolescents explained by personal social position and family socioeconomic status. International Journal for Equity in Health, 13, 26. http://doi.org/10.1186/1475-9276-13-26

Keith, T. Z. (2014). Multiple regression and beyond: An introduction to multiple regression and structural equation modeling. New York, NY: Routledge. 
Lawman, H. G., \& Wilson, D. K. (2012). A review of family and environmental correlates of health behaviors in high-risk youth. Obesity, 20, 1142-1157. http://doi.org/10.1038/oby.2011.376

Levin, K. A., \& Currie, C. (2014). Reliability and validity of an adapted version of the Cantril Ladder for use with adolescent samples. Social Indicators Research, 119, 1047-1063. http://doi.org/10.1007/s11205-013-0507-4

Lerner, R. M., \& Benson, P. L. (2003). Developmental assets and asset-building communities: Implications for research, policy and practice. New York, NY: Kluwer Academic/Plenum Publishers.

Lerner, R. M., \& Steinberg, L. (2009). The scientific study of adolescent development: Past, present, and future. In R. M. Lerner, \& L. Steinberg (Eds.), Handbook of adolescent psychology $\left(3^{\text {rd }}\right.$ Ed., pp. 3-14). Hoboken, NJ: John Wiley \& Sons.

Masten, A. S. (2001). Ordinary magic: Resilience processes in development. American Psychologist, 56, 227-238. http://doi.org/10.1037/0003-066X.56.3.227

Morgan, A., \& Haglund, B. J.A. (2009). Social capital does matter for adolescent health: evidence from the English HBSC study. Health Promotion International, 24, 363-372. http://doi.org/10.1093/heapro/dap028

Morgan, A., \& Ziglio, E. (2007). Revitalizing the evidence base for public health: An assets model. Global Health Promotion, 14(Supp. 2), 17-22. https://doi.org/10.1177/10253823070140020701x

Murphey, D. A., Lamonda, K. H., Carney, J. K., \& Duncan, P. (2004). Relationships of a brief measure of youth assets to health-promoting and risk behaviors. Journal of Adolescent Health, 34(3), 184-191. http://doi.org/10.1016/S1054-139X(03)00280-5

Proctor, C., Linley, P. A., \& Maltby, J. (2010). Very happy youths: Benefits of very high life satisfaction among adolescents. Social Indicators Research, 98, 519-532. http://doi.org/10.1007/s11205-009-9562-2

Roberts, C., Freeman, J., Samdal, O., Schnohr, C. W., De Looze, M. E., Gabhainn, S. N., ... International HBSC Study Group. (2009). The Health Behavior in School-aged Children (HBSC) study: Methodological developments and current tensions. International Journal of Public Health, 54, 140-150. http://doi.org/10.1007/s00038-009-5405-9

Ronen, T., Hamama, L., Rosenbaum, M., \& Mishely-Yarlap, A. (2016). Subjective well-being in adolescence: The role of self-control, social support, age, gender, and familial crisis. Journal of Happiness Studies, 17, 81-104. http://doi.org/10.1007/s10902-014-9585-5

Roth, J. L., \& Brooks-Gunn, J. (2003). Youth development programs: Risk, prevention and policy. Journal of Adolescent Health, 32(3), 170-182. http://doi.org/10.1016/S1054-139X(02)004214

Ryan, R. M., \& Deci, E. L. (2000). Self-determination theory and the facilitation of intrinsic motivation, social development, and well-being. American Psychologist, 55, 68-78. http://doi.org/10.1037/0003-066X.55.1.68

Scales, P. C. (1999). Reducing risks and building developmental assets: Essential actions for promoting adolescent health. Journal of School Health, 69, 113-119. http://doi.org/10.1111/j.1746-1561.1999.tb07219.x

Suldo, S. M., \& Huebner, E. S. (2006). Is extremely high life satisfaction during adolescence advantageous? Social Indicators Research, 78, 179-203. http://doi.org/10.1007/s11205-005$8208-2$

Vohs, K. D., \& Baumeister, R. F. (2004). Understanding self-regulation: An introduction. In R. F. Baumeister and K. D. Vohs (Eds.), Handbook of self-regulation: Research, theory, and applications (pp. 1-9). New York, NY: Guilford Press.

Youngblade, L. M., Theokas, C., Schulenberg, J., Curry, L., Huang, I.-C., \& Novak, M. (2007). Risk and promotive factors in families, schools, and communities: A contextual model of positive youth development in adolescence. Pediatrics, 119 (Supp. 1), S47-S53. http://doi.org/10.1542/peds.2006-2089H

Zimmerman, J. (2002). Achieving academic excellence: A self-regulatory perspective. In M. Ferrari (Ed.), The pursuit of excellence through education (pp. 85-110). New Jersey, NY: Erlbaum. 
Table 1.

Means, Standard Deviations and Correlations for all Variables.

\begin{tabular}{|c|c|c|c|c|c|c|c|c|c|}
\hline Variable & $(1)$ & $(2)$ & $(3)$ & $(4)$ & $(5)$ & $(6)$ & $(7)$ & $(8)$ & $(9)$ \\
\hline (1) Life satisfaction & & & & & & & & & \\
\hline $\begin{array}{l}\text { (2) Academic } \\
\text { achievement }\end{array}$ & $.18 * *$ & & & & & & & & \\
\hline $\begin{array}{l}\text { (3) Social } \\
\text { competence }\end{array}$ & $.30 * *$ & $.19 * *$ & & & & & & & \\
\hline (4) Self-regulation & $.23 * *$ & $.12 * *$ & $.36 * *$ & & & & & & \\
\hline (5) Life goals & $.16^{*}$ & $.15 * *$ & $.44 * *$ & $.26 * *$ & & & & & \\
\hline (6) Family support & $.28 * *$ & $.09 * *$ & $.38 * *$ & $.32 * *$ & $.22 * *$ & & & & \\
\hline (7) Peer support & $.19 * *$ & $.06 * *$ & $.43 * *$ & $.20 * *$ & $.25 * *$ & $.38 * *$ & & & \\
\hline $\begin{array}{l}\text { (8) Parental } \\
\text { monitoring }\end{array}$ & $.14 * *$ & $.09 * *$ & $.29 * *$ & $.19 * *$ & $.25^{* *}$ & $.32 * *$ & $.16^{* *}$ & & \\
\hline $\begin{array}{l}\text { (9) School } \\
\text { connectedness }\end{array}$ & $.27 * *$ & $.07 * *$ & $.16^{* *}$ & $.17 * *$ & $.07 * *$ & $.14 * *$ & $.20 * *$ & $.07 * *$ & \\
\hline$M$ & 7.24 & 2.46 & 5.21 & 3.53 & 4.14 & 5.80 & 6.04 & 3.52 & 4.15 \\
\hline$S D$ & 1.71 & .73 & .87 & .81 & .87 & 1.32 & 1.17 & .51 & .65 \\
\hline
\end{tabular}


Table 2.

Summary of the Sequential Regression Analysis for the Entire Sample with Individual Assets Entered before Social Assets.

\begin{tabular}{|c|c|c|c|c|c|c|c|c|c|c|}
\hline & \multirow[b]{2}{*}{ Predictors } & \multicolumn{3}{|c|}{ Model 1} & \multicolumn{3}{|c|}{ Model 2} & \multicolumn{3}{|c|}{ Model 3} \\
\hline & & $\beta$ & $t$ & $95 \% \mathrm{CI}$ & $\beta$ & $t$ & $95 \% \mathrm{CI}$ & $\beta$ & $t$ & $95 \% \mathrm{CI}$ \\
\hline \multicolumn{11}{|l|}{ Step 1} \\
\hline & Gender & -.054 & $-2.85 * *$ & $-.18,-.03$ & -.050 & $-2.79 * *$ & $-.17,-.03$ & -.029 & -1.64 & $-.13, .01$ \\
\hline \multirow{4}{*}{ Step 2} & Academic achievement & & & & 123 & $6.81 * * *$ & 09.16 & 116 & $6.66 * * *$ & 08,15 \\
\hline & Social competence & & & & .224 & $10.80 * * *$ & $.18, .26$ & .152 & $6.98 * * *$ & $.11, .19$ \\
\hline & Self-regulation & & & & .119 & $6.14 * * *$ & $.08, .15$ & .064 & $3.35^{* * * *}$ & $.03, .10$ \\
\hline & Life goals & & & & .021 & 1.07 & $-.02, .06$ & .014 & 0.73 & $-.02, .05$ \\
\hline \multicolumn{11}{|l|}{ Step 3} \\
\hline & Family support & & & & & & & .154 & $7.62 *$ & $.12, .20$ \\
\hline & Peer support & & & & & & & .000 & -0.02 & $-.04, .04$ \\
\hline & Parental monitoring & & & & & & & .011 & 0.58 & $-.03, .05$ \\
\hline & School connectedness & & & & & & & .198 & $11.19 * * *$ & $.17, .24$ \\
\hline & $R^{2}$ & .003 & & & .122 & & & .183 & & \\
\hline & $F$ change & $8.10^{* *}$ & & & $95.63 * * *$ & & & $81.56^{* * *}$ & & \\
\hline & $\Delta R^{2}$ & .003 & & & .119 & & & .060 & & \\
\hline & Square root $\Delta R^{2}$ & .054 & & & .345 & & & .245 & & \\
\hline
\end{tabular}

$* p<.05 ; * * p<.01 ; * * * p<.001$ 
Table 3.

Summary of the Sequential Regression Analysis for the Entire Sample with Social Assets Entered before Individual Assets.

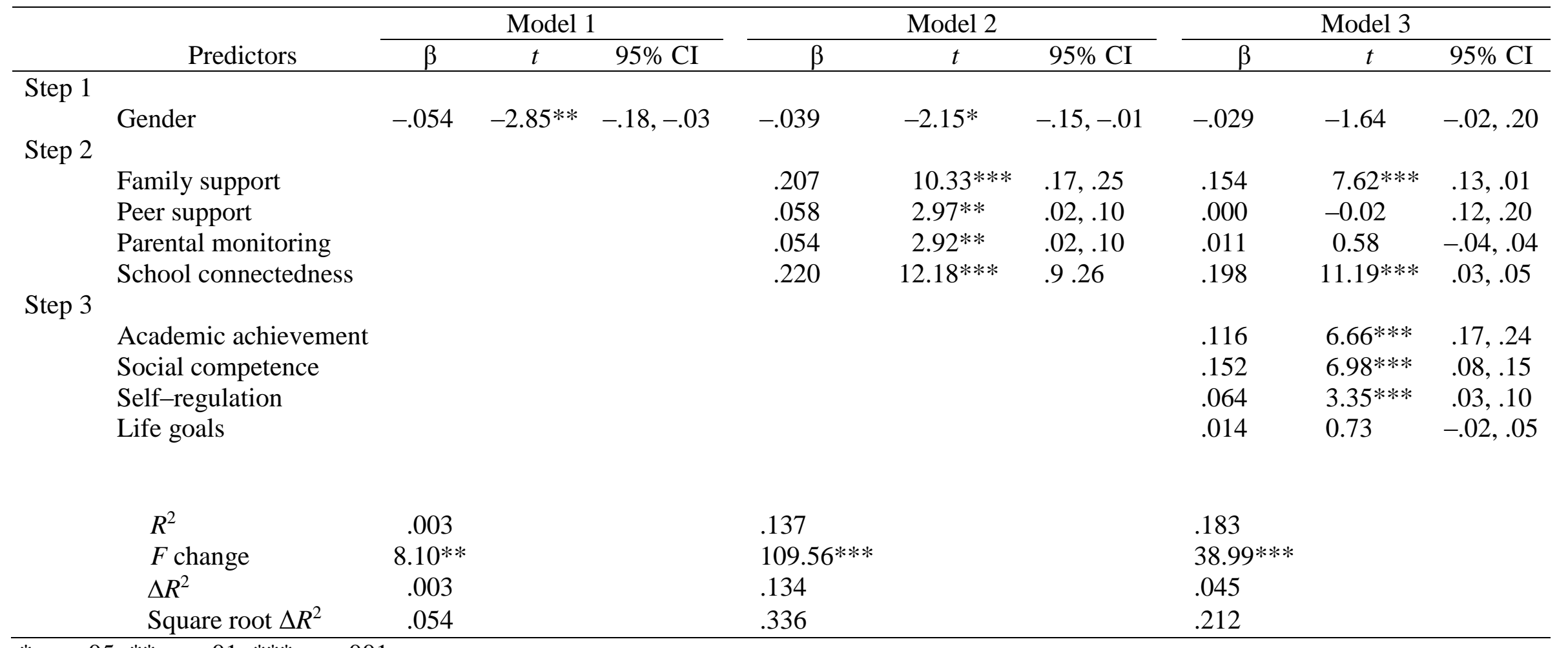

$* p<.05 ; * * p<.01 ; * * * p<.001$ 